\title{
A IMPORTÂNCIA DE UMA TRADUÇÃO PARA O PORTUGUÊS DE ZUR AUFFASSUNG DER APHASIEN - EINE KRITISCHE STUDIE, DE SIGMUND FREUD
}

\author{
Emiliano de Brito Rossi
}

\section{Considerações Preliminares}

Há uma lacuna a ser preenchida no caminho de quem empreende um estudo cronológico da obra freudiana traduzida para o português. Essa lacuna deve-se em grande parte ao desejo de Freud, que limitou à publicação, na edição alemã de suas obras completas, os textos pertinentes ao período psicanalítico propriamente dito, deixando ausente delas suas obras tidas como neurológicas.

Dentre as obras tidas por Freud como atinentes ao período neurológico de seus estudos encontra-se o livro Zur Auffassung der Aphasien - Eine kritische Studie, que nas páginas seguintes terá algumas passagens de sua história brevemente revisitadas e alguns de seus aspectos centrais esboçados.

Ernst Kris, um dos editores da tradução inglesa das Complete psychological works, na introdução ao volume The origins of psycho-analysis, publicado em 1954, conta-nos que:

Em 1939 Freud declinou de ter Zur Auffassung der Aphasien incluso no primeiro volume da edição alemã completa de seus trabalhos com o argumento de que o livro pertenceria aos seus trabalhos neurológicos e não aos psicanalíticos. Por outro lado em suas cartas ele o menciona com mais apreço do que seus outros trabalhos neurológicos. ${ }^{1}$ (p. 19)

Na edição inglesa, brevemente denominada Standard edition, o tradutor James Strachey, percebendo um parentesco incontestável entre vários aspectos dessa obra em relação ao conteúdo desenvolvido no texto metapsicológico Das Unbewußte, de 1915, decidiu tomar a liberdade de trazer, em anexo a esse texto traduzido para o inglês, apêndices dos quais constam algumas elaborações feitas já em 1891, ano de publicação da mesma.

\footnotetext{
${ }^{1}$ Todas as citações feitas a partir de textos em língua estrangeira foram traduzidas por mim, com exceção das cartas de Freud.
} 
Para o leitor de língua portuguesa a tradução das obras completas foi feita a partir da Standard edition. ${ }^{2}$ Desta advém o conhecimento por parte dos pesquisadores brasileiros da monografia de 1891. Em língua portuguesa, a editora portuguesa Edições 70 publicou uma tradução incompleta dessa monografia, feita, segundo consta dos dados catalográficos, a partir de uma tradução italiana de 1977. Hoje em dia o que se tem dessa tradução incompleta são apenas alguns parágrafos pinçados, ou seja, um mosaico do texto de 1891, a partir do qual não é possível refazer os passos então percorridos por Freud, ou seja, entender sua argumentação e conhecer a origem da lógica então utilizada para pensar o funcionamento do cérebro no que tange às atividades linguísticas e, posteriormente, transposta às suas obras psicanalíticas.

Este fato, somado à importância dessa obra para a compreensão da teoria psicanalítica, de suas origens e da linha de raciocínio traçada por Freud ao longo de sua vida de pesquisador e teórico, justifica, da perspectiva da comunidade científica, um trabalho de pesquisa sobre o livro Zur Auffassung der Aphasien, que se beneficiaria sobremaneira de uma tradução completa e feita diretamente da língua alemã para o português.

Segundo o psicanalista e biógrafo de Freud, Ernest Jones, citado por Wolfgang Leuschner no prefácio à nova edição alemã do livro em questão (Freud, 2001 [1891]), dos 850 exemplares impressos em 1891, 257 foram vendidos nos nove anos subsequentes à primeira publicação e o restante foi destruído. Antes da nova publicação alemã do livro, cuja primeira edição apareceu somente em 1992, Roland Kuhn, no prefácio à tradução francesa, escreve que "O livro tornou-se, nos dias de hoje, quase impossível de ser encontrado e está ausente de grandes bibliotecas” (Freud, 1983: 11).

Essa ausência da monografia freudiana sobre as afasias é responsável por várias dificuldades encontradas no estudo da psicanálise. Nesta, que é a primeira obra freudiana, encontram-se utilizados pela primeira vez vários conceitos que serão reiterados ao longo de toda a história da psicanálise. Não obstante essa questão conceitual, está igualmente presente na monografia a importante influência do neurologista inglês, John Hughlings Jackson, que forneceu as bases lógicas de entendimento genético do funcionamento do

\footnotetext{
${ }^{2}$ A editora Imago já publicou três volumes da obra freudiana traduzida diretamente do alemão pelo Dr. Luiz Alberto Hanns.
} 
cérebro e, por conseguinte, da aquisição e produção da linguagem, que, posteriormente, serviram para teorizar o funcionamento psíquico, da maneira como a psicanálise o entende.

Ludwig Binswanger, em "Freud et la constitution de la psychiatrie clinique", de 1936, diz que "sem o conhecimento e o reconhecimento exatos desse trabalho, nem uma compreensão histórica, nem uma compreensão hermenêutica das doutrinas freudianas são possíveis" (1970: 190).

Pierre Fédida, em seu prefácio à tradução francesa do livro Language and the origins of psychoanalysis, de John Forrester, reafirma a importância do livro inaugural de Freud, dessa vez, contudo, de uma perspectiva psicanalítica. Vejamos:

É legítimo lembrar que se trata do primeiro livro de Freud e que a reflexão crítica da qual ele é testemunha vale de prolegômeno às teses defendidas em A interpretação dos sonhos e, por conseguinte, constantemente argumentadas. Não é, portanto, somente em função da teoria das representações (representação de objeto e representação de palavra) e de uma concepção da associatividade de ideias que o ensaio sobre as afasias merece ser visto como dispondo as condições da teoria do sonho. Assim sendo, Forrester nota: "é sobre essa relação entre a localização das palavras e a estrutura do sistema nervoso que o estudo de Freud sobre a afasia devia se mostrar de uma importância capital". Se devemos tomar ao pé da letra a ideia de que a linguagem está nas origens da psicanálise, o ensaio sobre as afasias merece ser considerado como uma passagem teórica obrigatória da descoberta da psicanálise. (Forrester, 1984: 22)

\section{Aspectos neurológicos centrais de Zur Auffassung der Aphasien - Eine kritische Studie \\ Para que possamos nos aproximar do mérito debatido no livro inaugural de} Sigmund Freud e para termos uma clara noção de sua importância, cabe-nos, a princípio, apresentar uma síntese de seu conteúdo. Em primeiro lugar, essa síntese pode ilustrar-nos a cena na qual um personagem então periférico, o jovem Sigmund Freud, se inseriu para questionar aspectos hegemonicamente defendidos e aceitos pelos grandes teóricos da neuropatologia do final do século XIX. Por outro lado, essa breve descrição poderá apontar alguns dos elementos que tornam esse estudo de Freud uma privilegiada fonte de conceitos e de formas de compreensão do funcionamento psíquico que seriam posteriormente desenvolvidos no percurso da construção da psicanálise.

Cabe uma ressalva, porém, antes de passarmos à síntese. Segundo Greenberg:

A auto-identificação de Freud como um neuropatologista na capa do livro sobre as afasias, um lembrete de que a neuropatologia ainda era um de seus interesses centrais em 1891, 
traça uma linha teórica que vai até seu 'Projeto' de 1895 e indica que a investigação sobre as afasias tem a ver com a correlação entre sintomas da linguagem e danos específicos dos tecidos do cérebro, e, destarte, requer uma teoria ou teorias sobre locais e funções da linguagem no cérebro. (1997: 13)

Greenberg sublinha em nota de rodapé:

Walter Riese chama atenção para uma importante consideração: "O termo 'neuropatologia' era usado, nos dias de Freud e nos países de língua alemã, num sentido bem diferente daquele que o termo finalmente assumiu em nossos dias e, particularmente, nos Estados Unidos. À época de Freud e em seu próprio país, neuropatologia não era entendida como sendo meramente uma parte da patologia, ou seja, a investigação de tecido nervoso alterado; seu primeiro propósito era muito mais o de investigar locais e tipos de lesões cerebrais com a finalidade última de correlacioná-los a funções e comportamentos perturbados". (p. 13)

Após localizarmos o sentido do termo "neuropatologia" no século XIX e a vinculação profissional de Freud a essa área de investigações, vamos à breve síntese, primeiramente em uma perspectiva neurológica, do conteúdo de Zur Auffassung der Aphasien, para, posteriormente, indicar seu valor como um texto fundamental para a posterior teorização da psicanálise:

Brun (1936) comenta a obra: "Freud faz uma distinção precisa entre projeção periférica (e espinhal) e a representação cortical central das partes do corpo no órgão central e diz que as áreas periféricas do corpo não se encontram representadas localmente, mas exclusivamente de forma funcional na porção superior do cérebro. Além disso, ele declina-se firmemente a localizar ideias em áreas localmente circunscritas do cérebro ("centros") e, ao invés disto, explica a função da linguagem geneticamente (em termos de aquisição gradual na infância) como sendo o resultado da re-estimulação de uma vasta rede de associação visual, acústica, tátil, cinestésica etc. Era a ruptura dessa rede de associação e não a destruição de quaisquer centros especiais motores, sensórios ou de 'compreensão', que levava ao 'colapso' das funções de linguagem e, assim, produzia as várias formas de afasia. Finalmente, ele foi, ainda, o primeiro a dar ênfase especial ao trabalho de Hughlings Jackson e à teoria da 'involução' daquele aparelho [de linguagem], altamente organizado, sob condições patológicas, que foi introduzida à patologia por aquele brilhante médico inglês, mas que, infelizmente, foi ignorada. Nessa frutífera obra, Freud finalmente propôs a concepção de agnosia (para descrever distúrbios da capacidade de reconhecer objetos, que fora anteriormente confundida com a 'assimbolia' de Finkelnburg); essa ideia é bem conhecida por ter se tornado, subsequentemente, uma ideia muito frutífera na patologia do cérebro e por ter se tornado aceita de forma geral. Se considerarmos a clareza com a qual Freud, passo a passo, desenvolveu todos esses modernos pontos de vista em seu excepcional estudo patológico do cérebro já nos idos de 1891, então não precisamos hesitar em 
descrevê-lo como o predecessor mais importante de Monakow. ${ }^{3}$ Parece-me ser um ato de justiça histórica e dever científico declarar isso especificamente nos dias de hoje". (Kris, 1954: 18-19)

Para aqueles que desconhecem que as teses hegemonicamente defendidas à época em que o livro sobre as afasias foi escrito eram precisamente opostas às defendidas por Freud, o caráter crítico e o gesto de ruptura presentes no livro freudiano se perdem. Vamos por partes revendo os pontos levantados na citação anterior para podermos ter em mente as mudanças por ele advogadas na concepção do cérebro e de seu funcionamento.

Naquela época havia a suposição de que todas as partes periféricas do corpo teriam um correlato no tecido do córtex cerebral. É uma ideia que se assemelha à de um homúnculo desenhado na superfície cortical do cérebro em que existiria uma projeção de 1:1 das partes periféricas do corpo sobre o córtex. Além disso, as memórias de estímulos percebidos seriam armazenadas, de forma inalterada, uma por uma em células corticais. Assim, o córtex seria uma espécie de recipiente de memórias. Daí a possibilidade de se pensar em centros específicos da linguagem, como os de Wernicke e Broca, os dois maiores expoentes das teorias localizacionistas do cérebro, respectivamente para as representações sensórias e motoras da linguagem.

Meynert, então professor de Freud, defendia a ideia de que cada palavra ouvida ou lida, ou seja, cada estímulo sonoro ou visual percebido, fosse guardado em uma célula em uma área definida do cérebro, a área de Wernicke e, em contrapartida, a memória do movimento que se faz para falar e para escrever fosse, igualmente, guardada nas células, só que dessa vez em um outro centro, o centro motor ou área de Broca. Os distúrbios afásicos seriam explicados, então, como uma destruição de um desses centros ou como a destruição dos feixes de condução que ligariam esses dois centros diversos.

Quanto à teoria de Jackson, segundo a qual o aparelho de linguagem sofreria uma involução, de um estágio de organização mais avançado, mais complexo, para um estágio menos avançado, mais simples, em reação a um distúrbio, funcional ou anatômico, ela foi aceita por Freud e serviu de base para a concepção da forma com que o aparelho psíquico se desenvolveria e adoeceria. A noção de agnosia, formulada por Freud e aceita pela

\footnotetext{
3 Constantin Von Monakov (1853-1930), histologista suíço.
} 
comunidade científica até os dias de hoje, também é fruto das reflexões presentes nessa monografia.

\section{Importância de Zur Auffassung der Aphasien - Eine kritische Studie}

Nesta seção do presente artigo será dado início ao aprofundamento de questões relativas ao contexto histórico de Zur Auffassung der Aphasien a partir de comentários tecidos tanto pelo autor como por alguns de seus leitores. Essas considerações nos darão a dimensão da importância da obra vista de perspectivas diferentes. Uma delas, a do próprio Freud, seja na época em que a publicou e experimentou suas primeiras repercussões, seja décadas mais tarde, ao relembrá-la, já após um longo percurso de construção da psicanálise. A segunda perspectiva é a ideia de que haja elementos fundamentais da psicanálise que se encontram nela presentes, de forma desenvolvida ou em estágio embrionário, e que, por isso, o estudo crítico sobre as afasias traz consigo uma série de pistas esclarecedoras de várias articulações centrais na teoria psicanalítica que minha pesquisa de doutorado pretende fazer dialogar com os Estudos de Tradução.

\subsection{Caráter de ruptura de Zur Auffassung der Aphasien}

Texto inaugural de Freud, Zur Auffassung der Aphasien marca uma ruptura com a comunidade científica na qual ele nasceu e apresenta algumas das condições de possibilidade para o surgimento da psicanálise. Segundo Grubrich-Simitis (1993: 349):

Não se pode dizer com clareza quando a expressão "pré-psicanalítico" se tornou usual. Em seus próprios escritos, nos quais Freud vem a mencionar suas primeiras publicações, parece que ele, em todo o caso, não a tenha utilizado. Conquanto o adjetivo de fato emerja, ele serve quase sempre à indicação de épocas e disciplinas às quais uma compreensão do psíquico ainda escapava totalmente, e não à caracterização de seus primeiros trabalhos.

A crítica de Freud a seus mestres, às doutrinas hegemônicas sobre o funcionamento do cérebro, principalmente em relação à produção de linguagem, e a articulação entre somático (ou anátomo-fisiológico) e psíquico, ou, melhor dizendo, entre estímulo nervoso e representação, posto que o conceito de aparelho psíquico ainda teria de ser desenvolvido, constituiu-se como um movimento de ruptura e foi, ao mesmo tempo, um movimento fundador da psicanálise, ao menos da noção de aparelho de linguagem, "irmão mais velho" 
(Stengel, apud Rizzuto, 1993: 113) do aparelho psíquico. Sobre a divisão desses dois períodos, neurológico e psicanalítico, da vida profissional de Freud, Grubrich-Simitis tece o seguinte comentário:

Essa divisão introduzida pelo autor e herdada após sua morte mostrou-se, num olhar retrospectivo, em todo o caso, presumivelmente artificial, já que, num olhar mais atento se tornaria claro que Freud em vários de seus escritos supostamente puramente neurológicos já se encontra em seu caminho para a psicanálise. [nota de rodapé: Ao final da carta (...), enviada a Jelliffe, na qual Freud reagia a um manuscrito enviado por ele sobre o tema 'Sigmund Freud como neurologista', Freud acrescenta que o artigo sobre seus primeiros trabalhos, mantidos afastados dele nesse meio tempo, poderia impressionar ao menos àqueles que ainda "gostam de achar que eu tirei a psicanálise da cartola".]. (GrubrichSimitis, 1993: 349-50)

Indiquemos, neste momento, algumas passagens em que Freud tem em consideração seu estudo crítico sobre as afasias e contextualiza o momento de sua aparição. Essas passagens se distanciam cronologicamente e dão uma ideia de como o texto foi concebido, teve sua recepção digerida e, finalmente, vários anos depois, foi relembrado. No dia 2 de maio de 1891 Freud escreveu a seu amigo Flie $\beta$ :

Dentro de poucas semanas, darei a mim mesmo o prazer de enviar-lhe um pequeno livro sobre a afasia, pelo qual eu próprio nutro um sentimento caloroso. Nele, sou muito despudorado, terço armas com seu amigo Wernicke, com Lichtheim e Grashey, e chego até a arranhar o poderosíssimo ídolo Meynert. Estou muito curioso de ouvir o que o Sr. terá a dizer sobre esse esforço. Em vista de seu relacionamento privilegiado com o autor, parte dele há de soar-lhe familiar. O artigo, aliás, é mais sugestivo do que conclusivo. (Freud, apud Masson, 1986: 28)

Esse artigo crítico, "mais sugestivo que conclusivo", foi escrito pelo então neuropatologista, que, além de suas preocupações com as paralisias cerebrais de crianças, já estava envolvido de forma direta com as paralisias histéricas, havendo, inclusive, publicado traduções de trabalhos de Charcot para o alemão. Em 1925, em sua "Auto-descrição" (Selbstdarstellung), Freud relembra a época do surgimento da monografia:

No período entre 1886-1891 trabalhei pouco na produção científica e não publiquei quase nada. Eu estava imbuído de me adaptar ao novo trabalho e de garantir minha existência material, bem como a de minha família, que crescia rapidamente. Em 1891 apareceu o primeiro dos trabalhos sobre a paralisia cerebral das crianças, escrito em parceria com meu amigo e assistente, Dr. Oskar Rie. No mesmo ano uma encomenda de colaboração em um 
pequeno léxico da medicina ensejou a discussão sobre a doutrina das afasias, que era, à época, governada pela perspectiva puramente localizacionista de Wernicke e Lichtheim. Um pequeno livro crítico-especulativo, "Zur Auffassung der Aphasien", foi o fruto deste esforço. (Freud, 1925d: 41-42)

Por ser um trabalho de ruptura com doutrinas hegemonicamente aceitas, a recepção do estudo crítico não foi a esperada. Ao invés do reconhecimento do rigor de sua argumentação e do valor de suas ideias, o que se viu foi um "respeitável fracasso" (Freud, apud Masson, 1986: 74). A dedicatória do livro foi endereçada ao Sr. Dr. Josef Breuer, "em amigável honorificência" (Freud 2001 [1891]: 39), mas Breuer não pôde apreciá-la. Em 13 de julho de 1891, ele escreve a Minna Bernays:

O livro sobre as afasias já me causou muito desgosto. A recepção de Breuer foi deveras estranha; ele quase não me agradeceu pela dedicatória, ... não conseguiu lembrar-se de nenhum de seus méritos e, no final, tentou amenizar dizendo que o livro tinha sido muito bem escrito." ${ }^{4}$ (Freud, apud Rizzuto, 1989: 112)

Em carta dirigida a Fließ, datada de 21 de maio de 1894, Freud disse:

Estou bem sozinho aqui, na elucidação das neuroses. Sou encarado como uma espécie de monomaníaco, embora tenha a nítida sensação de haver tocado num dos grandes segredos da natureza. Há algo de curioso na incongruência entre o apreço que se dá ao próprio trabalho intelectual e o valor que os outros lhe atribuem. Veja esse livro sobre as diplegias, que arrumei às pressas, com um mínimo de interesse e esforço, quase com frivolidade. Tem alcançado um sucesso tremendo. [...] E, das coisas realmente boas, como a Afasia, as "Ideias Obsessivas", que agora ameaçam sair em texto impresso, e a futura "Etiologia e Teoria das Neuroses", nada posso esperar além de um respeitável fracasso. (Freud apud Masson, 1986: 74)

A despeito da falta de reconhecimento imediato por parte da comunidade científica à qual o livro visou, a monografia sobre as afasias teve seu valor reconhecido por Freud, fato que pode ser constatado pela ubiquidade de alguns conceitos ali inaugurados ao longo de sua obra psicanalítica e por seus comentadores, pelo menos desde a década de 1930.

\subsection{Recepção do livro em algumas tradições de estudos psicanalíticos}

A primeira tradução de Zur Auffassung der Aphasien foi feita para o inglês em 1953, por Stengel. De acordo com Greenberg (1997: 1): “O interesse pelo 'primeiro Freud'

\footnotetext{
${ }^{4}$ Grifos da autora.
} 
vem crescendo, particularmente entre analistas; mas restam lacunas significativas, em parte porque a tradução de seus primeiros trabalhos está apenas começando". Sobre a importância histórica do estudo, o próprio Stengel escreve:

Nesse tratado, Freud desafiou, pela primeira vez, teorias aceitas de forma corrente e colocou novas teorias em seus lugares. Mais importante ainda: foi o primeiro de seus escritos a lidar com atividades mentais. Ele apareceu apenas alguns anos antes de Freud, finalmente, ter se voltado à psicopatologia. Assim sendo, se qualquer dos escritos pré-psicanalíticos de Freud poderia lançar alguma luz sobre a relação entre os dois períodos de sua vida profissional e, destarte, sobre a origem de conceitos psicanalíticos, esse livro era o livro sobre as afasias. (Stengel, 1954: 85)

Birman comenta a recepção do livro e suas traduções em algumas das tradições de estudos psicanalíticos:

Apesar do esquecimento geral existem diferenças significativas, entre as diversas tradições psicanalíticas, nas relações que estabeleceram com esse ensaio primordial. As tradições alemã, inglesa e norte-americana já lidam com o texto há algumas décadas, desde a década de 50 e, no final dos anos setenta, surgiu uma edição em espanhol, publicada em Buenos Aires. Na França, apenas nos anos 80 o ensaio teve a sua primeira edição, numa bem elaborada tradução. Finalmente, na década de 70 surgiu uma edição em língua portuguesa [feita a partir do italiano], mas incompleta, pois faltam alguns capítulos. (Birman, 1993: 42)

Para se poder ter uma noção exata do contexto em que o estudo sobre as afasias inaugura o uso de conceitos e, ao mesmo tempo, concebe a lógica que será transposta ao funcionamento do aparelho psíquico, é necessário que se tenha conhecimento do embate que estava sendo travado durante a totalidade do livro de 1891. Na tradição psicanalítica brasileira, ou lusófona, resta, até os dias de hoje, essa lacuna a ser preenchida, ou seja, uma tradução completa feita diretamente da língua alemã.

Os comentários referentes ao estudo crítico de Freud feitos em língua portuguesa ainda têm de apoiar-se no texto original, em uma tradução parcial e indireta, ou em traduções para outras línguas e em comentários produzidos em outras tradições de recepção da psicanálise. Entretanto, sua importância já é conhecida, mesmo que de forma restrita, e há algumas considerações produzidas em português sobre esse estudo. Sobre o caráter de transição representado pela monografia sobre as afasias, escreve Birman: 
Com a realização desse estudo Freud se encontra no limiar de um recomeço, no campo da teoria e no de sua existência pessoal, onde esses diferentes registros se articulam intimamente na transformação de seus referenciais de mestria. Daí o estudo sobre as afasias ter como subtítulo "um estudo crítico", materializando a ruptura freudiana com o pensamento neurológico estabelecido na instituição universitária, a ruptura com a psicologia mecanicista de base neuroanatômica e anunciando simultaneamente a ruptura com a psicologia intelectualista centrada na consciência. (Birman, 1993: 48)

Para iniciarmos uma consideração mais específica sobre a origem de conceitos psicanalíticos na monografia sobre as afasias e sobre os deslocamentos sofridos por alguns conceitos que vieram do arcabouço da neuropatologia do século XIX que, tendo ou não seu significado alterado, adquiriram um papel proeminente na teoria psicanalítica, vejamos, agora, um comentário de Kuhn:

Freud já adotava, em seu estudo sobre a afasia, a atitude pregada por Conrad, apropriandose da perspectiva "dinâmica e funcional" de Jackson, em oposição a uma perspectiva "estática e morfológica" defendida por seu mestre Meynert e, com ele, por Wernicke e Lichtheim. Mas nós já fizemos notar mais de uma vez que Freud se apropria da terminologia de pesquisadores desaprovados por ele.

A análise e a tomada de partido de Freud tornam evidente que ele abrigava em si o mesmo conflito que se desenrolou em grande escala na história da afasia entre concepções científicas opostas e isso durante mais de uma centena de anos. Para Freud tratava-se manifestamente de problemas essenciais e profundos concernindo às relações psicológicas entre o somático-biológico e o psicoespiritual. Da mesma forma que no movimento de pesquisa científica, esses problemas atingem seu ponto crítico para Freud lá aonde eles se mostram o mais misteriosos, mas igualmente, o mais suscetíveis de poderem aceder a uma solução, ou seja, no domínio da linguagem humana. De igual maneira, desde sempre, constatou-se que vias devem ser encontradas, a partir dos problemas da linguagem, para que se adquira um certo conhecimento sobre o fenômeno da linguagem no ser humano normal. (Freud, 1983: 28-29)

Como mencionado acima, Freud foi incumbido de realizar uma pesquisa sobre as doutrinas das afasias como elas se haviam desenvolvido até aquele momento. Durante suas pesquisas ele se deparou com algumas inconsistências presentes nos esquemas fornecidos por Wernicke e Lichtheim para a explicação dos quadros clínicos afásicos conhecidos. O esquema de Wernicke-Lichtheim baseava-se na suposição de centros de linguagem circunscritos ao córtex cerebral (M, centro motor, ou área de Broca e A, centro sensorial, ou área de Wernicke. Além desses dois centros haveria um terceiro, B, um centro difuso que representaria as vias de condução comunicantes entre os dois primeiros centros). Os 
diferentes tipos de afasia seriam ocasionados, pois, pela destruição desses centros ou pela destruição das vias de condução entre eles. Segundo Leuschner:

O esquema de Wernicke-Lichtheim não teria podido explicar satisfatoriamente um sintoma afásico específico, a saber, o da parafasia. Esse distúrbio de linguagem explicava-se de forma mais apropriada - entretanto somente por uma perspectiva psicológica - se fosse suposto "que a representação de palavra é conectada através de sua extremidade sensível (por intermédio das imagens do som) à representação de objeto". Neste ponto Freud se associa à ideia de Kußmaul, que havia afirmado que o falar aconteceria sempre somente por meio da imagem do som. A via de condução BM, concluiu Freud, não existiria nem em termos anatômicos, nem em termos funcionais. O quão importante é essa afirmação se tornará claro quando se tiver em mente que Freud equiparou, em sua posterior teoria psicanalítica, toda a questão sobre a consciência a uma ideia contendo basicamente essa conexão entre representações de palavra e representações de coisa. Ele localizou a fronteira entre os sistemas consciente e inconsciente entre essas duas representações. Creio que se tenha razão em afirmar que esse complexo seja, em seu todo, o protótipo do aparelho psíquico da forma com que Freud o acabou de formular, então, no capítulo 7 de $A$ interpretação dos sonhos.

$\mathrm{O}$ aparelho de linguagem construído no trabalho sobre as afasias permitiu a Freud, então, delimitar e definir o objeto de sua nova psicologia e satisfazer-se, sem ter necessariamente de lançar mão de um terceiro elemento, nem de um substrato patológicoanatômico, nem de um espírito. (Freud, 2001 [1891]: 26)

\section{Para Grubrich-Simitis:}

O trabalho de investigação sobre os distúrbios de linguagem se impôs a Freud em função de questões com as quais ele se deparou em seus estudos sobre as paralisias histéricas, ou seja, inserido diretamente no contexto da descoberta do inconsciente. Ele pode ter esperado dos pesquisadores contemporâneos do cérebro uma explicação fisiológica sobre o efeito de representações patógenas inconscientes. Na medida em que se distanciou criticamente de suas concepções, após uma cuidadosa investigação, obrigou-se, por assim dizer, a empreender, a partir da análise do aparelho de linguagem, a conceitualização psicanalítica do aparelho anímico. Por causa de sua extraordinária postura diante "da delimitação do ponto de vista fisiológico do psicológico", mas também por causa da beleza da descrição e da autoconsciência da originalidade do seu desenvolvimento de ideias, o estudo deve ser tido em conta, além disso, como a primeira efetiva obra prima freudiana. (1993: 36)

Ao invés de encontrar as respostas que buscava nos teóricos hegemonicamente aceitos por suas doutrinas sobre as afasias, quem forneceu várias ideias de alto valor heurístico foi um pesquisador inglês, John Hughlings Jackson, praticamente ignorado à época. Das ideias desse último, Freud apropriou-se e construiu a partir delas sua concepção de funcionamento do aparelho de linguagem, ou seja, o mecanismo de aquisição da linguagem materna e de línguas estrangeiras, bem como a forma com que o aparelho 
reagiria, seja a lesões do tecido cerebral, seja a problemas funcionais. Leuschner cita as palavras de Freud:

\begin{abstract}
"Iniciamos com a frase de Hughlings Jackson, para a apreciação do funcionamento do aparelho de linguagem sob condições patológicas, segundo a qual todos esses modos de reação representam casos de regressão funcional [...] do aparelho altamente organizado e, assim sendo, correspondem a estados anteriores em seu desenvolvimento funcional. Uma ordenação de associações mais avançada, desenvolvida posteriormente, é, sob todas as condições, perdida e uma ordenação mais simples, primariamente adquirida, mantém-se conservada." De fato são essas frases que se leem como projetos para as descrições posteriores da origem dos sintomas neuróticos. (2001 [1891]: 22)
\end{abstract}

\title{
3.3. Início da discussão sobre conceitos psicanalíticos inaugurados em Zur Auffassung der Aphasien
}

Podemos trazer, agora, uma pequena amostra de alguns conceitos que tiveram seu primeiro aparecimento no estudo sobre as afasias. Segundo Stengel:

O livro contém uma série de termos que se tornaram palavras familiares na psicanálise. "Projection" foi usado, em seu sentido original, como um conceito puramente anatômico e fisiológico. Freud propôs o termo "representação" para um certo tipo de projeção, a saber, aquelas advindas da periferia do corpo para as estruturas nervosas superiores.

O termo Besetzung, que na literatura psicanalítica inglesa tem sido traduzido como cathexis e em francês por l'investissement, aparece aqui neste escrito freudiano pela primeira vez. ${ }^{5}$ Ele o usou na discussão sobre a teoria de Meynert sobre o investimento de função em células corticais não utilizadas. Apesar de rejeitar a hipótese de Meynert, ele utilizou posteriormente o termo num sentido similar, apesar de ser psicodinâmico, para o mecanismo do investimento de objeto com libido.

O conceito de "sobredeterminação", da mesma forma, foi definido pela primeira vez em relação a funções de linguagem que foram supostas como salvaguardadas contra colapso por uma multiplicidade de mecanismos.

Essas instâncias ilustram como conceitos de dinâmica fisiológica foram retirados de seus solos originais e transplantados para o campo da psicodinâmica. (1954: 86)

Para tentarmos caracterizar o aparelho de linguagem, importante construção teórica para o diálogo entre psicanálise e tradução, é necessário considerarmos os conceitos de representação de objeto e representação de palavra, inaugurados em 1891 e que forneceram as bases linguísticas para a construção do aparelho psíquico tal como é exposto em 1900 no capítulo VII de A interpretação dos sonhos, além de reaparecerem em outros textos, tais como "O inconsciente", de 1915, sendo, pois, conceitos centrais na teoria psicanalítica.

\footnotetext{
5 Para uma leitura mais cuidadosa desse delicado termo em alemão e suas possíveis traduções, ver Hanns (1996: 89-100).
} 
Freud partiu dos estudos neuropatológicos e da noção de que para a psicologia a unidade básica da função de linguagem seria a palavra, e concluiu que sua descrição apropriada seria a de uma representação complexa composta de elementos acústicos, visuais e cinestésicos (2001 [1891]: 117). Assim sendo, o complexo da representação de palavra compõe-se da imagem do som da palavra, da imagem visual das letras, da imagem do movimento da fala e da imagem do movimento da escrita. A palavra, contudo, só adquire seu significado na ligação com a representação de objeto, ao menos no que tange aos substantivos e adjetivos (p. 122). É nessa ligação que Freud postula o fenômeno da consciência e reserva à esfera inconsciente a presença exclusiva das representações de objeto. Estas, por sua vez, são complexos associativos das mais variadas imagens visuais, acústicas, táteis, cinestésicas, entre outras, advindas das impressões sensíveis dos objetos (p. 122).

A representação de palavra é, nos termos de Freud, um complexo fechado, mas passível de ser aumentado (p. 122). Para cada palavra, como vimos acima, há algumas imagens específicas, no entanto, quando aprendemos, por exemplo, a associar a imagem da letra cursiva à imagem da letra de fôrma, ou quando associamos duas pronúncias diferentes da mesma palavra, percebendo entre elas uma identidade, há o que se denomina superassociação. Ainda, quando associamos duas palavras de línguas estrangeiras ocorre o mesmo fenômeno da superassociação (p. 104 e 132).

A representação de objeto, por sua vez, é um complexo aberto, sempre passível de abrigar novas imagens táteis, visuais, cinestésicas, olfatórias etc. Dessa característica peculiar advém um dos modos de compreensão da plasticidade da memória. Como dito anteriormente, percepção e associação são dois nomes para um mesmo processo (p. 100). Não há percepção sem associação imediata daquilo percebido. Há então o entrelaçamento de várias imagens componentes das representações de objeto, o que servirá posteriormente para a elaboração, juntamente com as noções de deslocamento e condensação, do modo de funcionamento do processo primário no aparelho psíquico.

No início do processo de aprendizado da linguagem haveria, em primeiro lugar, as percepções e suas automáticas associações - posto que esses dois nomes nada mais são do que dois nomes para um mesmo processo - das falas dos outros. Para o infante, aprender a falar representa fazer tentativas sucessivas de aproximar ao máximo a imagem de som por 
ele produzida daquela que foi anteriormente ouvida. Há, pois, uma imagem de som de palavra (Wortklangbild) primeiramente associada à sensação da inervação da palavra (Wortinnervationsgefühl). Quando falamos, passamos a possuir uma representação ${ }^{6}$ do movimento da fala (Sprachbewegungsvorstellung) de modo que para nós a "palavra" é duplamente determinada por imagens de movimento. Além disso, após falarmos, ou seja, após a primeira tentativa balbuciante, obtemos uma nova imagem de som da palavra falada. Antes que a fala se torne completamente articulada não é necessário e nem possível que os dois sons de palavra sejam iguais, mas somente associados entre si (Freud, 2001 [1891]: 117).

É no contexto do desenvolvimento dessa construção teórica, que se torna cada vez mais complexa para abranger as explicações dos processos do falar articulado, do soletrar, do ler, do escrever etc., que ocorre o primeiro uso do adjetivo "sobredeterminado" (“"̈̈berbestimmt”) (p. 118), termo que será retomado e reformulado nos Estudos sobre a Histeria de 1895, para referir-se às diversas causas de um sintoma.

\section{Considerações finais}

Dado o caráter inconcluso desta pesquisa, gostaríamos de dizer que ainda resta uma série de considerações a serem desenvolvidas. Entre essas, podem ser adiantadas a íntima relação entre as reflexões propostas no texto de 1891 e aquelas presentes nos Estudos sobre a Histeria, de 1895. Outros textos psicanalíticos, como, por exemplo, a Traumdeutung, Das Unbewußte e Zur Psychopathologie des Alltagslebens, também devem ensejar comentários no sentido de vincular o início das elaborações presentes no estudo de 1891 a seus desdobramentos neles desenvolvidos.

Espero ter demonstrado brevemente, com esse apanhado de ideias, a importância de se ter em português uma tradução de Zur Auffassung der Aphasien completa e feita diretamente da língua alemã para o português do Brasil. Sem a menor pretensão de constituir uma exposição exaustiva, tendo em vista que vários aspectos importantes foram deixados de fora destas páginas, espero ter esboçado alguns aspectos relativos tanto à importância do livro inaugural de Sigmund Freud, bem como algumas passagens de sua recepção em algumas tradições de difusão e construção da psicanálise.

\footnotetext{
6 Nesse contexto "representação" é sinônimo de "imagem".
} 


\section{Referências Bibliográficas:}

BINSWANGER, Ludwig (1970 [1936]) "Freud et la constitution de la psychiatrie clinique". Discours, parcours et Freud. Paris: Gallimard.

BIRMAN, Joel (1993) Ensaios de teoria psicanalítica, 1a. parte: metapsicologia, pulsão, linguagem, inconsciente e sexualidade. Rio de Janeiro: Jorge Zahar.

FORRESTER, John (1984) Le langage aux origines de la psychanalyse. Traduit de l'anglais par Michelle Tran van Khai. Préface de Pierre Fédida. Paris: Gallimard.

FREUD, S. (2001 [1891]) Zur Auffassung der Aphasien - eine kritische Studie. Frankfurt am Main: Fischer Taschenbuch Verlag.

(1925) "Selbstdarstellung". Gesammelte Werke. Chronologisch geordnet. Band XIV. Frankfurt am Main: S. Fischer Verlag.

(1953) On aphasia. Translation and Introduction by E. Stengel. London: Imago.

(1983) Contribuition à la conception des aphasies. Une étude critique. Préface de Roland Kuhn. Traduit par Claude van Reeth. Paris: PUF.

GREENBERG, Valerie D. (1997) Freud and his aphasia book - language and the sources of psychoanalysis. Ithaca and London: Cornell University Press.

GRUBRICH-SIMITIS, Ilse (1993) Zurück zu Freuds Texten. Stumme Dokumente sprechen machen. Frankfurt am Main: S. Fischer.

KRIS, Ernst (1954) The origins of psycho-analysis. Letters to Wilhelm Fliess, drafts and notes: 1887-1902. Edited by Marie Bonaparte, Anna Freud, Ernst Kris. Translation by Eric Mosbacher and James Strachey. Introduction by Ernst Kris. London: Imago.

MASSON, J. M. (1986) A correspondência completa de Sigmund Freud para Wilhelm Fliess - 1887-1904. Editado por Jeffrey Moussaieff Masson; Trad. de Vera Ribeiro. Rio de Janeiro: Imago.

RIZZUTO, Ana-Maria (1989) "A hypothesis about Freud's motive for writing the monograph 'On Aphasia'”. International Journal of Psycho-Analysis 16, 111-117.

(1993) "Freud's speech apparatus and spontaneous speech". International Journal of Psycho-Analysis 74, 113-127.

STENGEL, E. (1954) “A re-evaluation of Freud's book On aphasia. Its significance for Psycho-Analysis”. International Journal of Psycho-Analysis 35, 85-89. 